\title{
Transparent Conductive Layers for Organic Solar Cells - Simulation and Experiment
}

\author{
Jan Meiss, Nikola Allinger, Christiane Falkenberg, Karl Leo, and Moritz Riede \\ Institut für Angewandte Photophysik, Technische Universität Dresden, George-Bähr-Straße \\ 1, 01062 Dresden, Germany; http://www.iapp.de
}

\begin{abstract}
Thin metal films are a desirable alternative to indium tin oxide for utilization in organic solar cells (OSC). We describe background and processing parameters for thin metal films and show examples of top-illuminated OSC employing metal electrodes. Simulations are introduced as tool for OSC fabrication; several pitfalls are presented which must be considered for successful numerical treatment of thin-film layers at coalescence thicknesses and for coherent treatment.
\end{abstract}

Keywords: metal film, simulation, solar cell, ITO, transparent electrode, small-molecule, conductive polymer, capping layer, doping

Compared to inorganic solar cells, the field of small-molecule organic solar cells (SM-OSC) is a rather new area of research, but has become the subject of intense activities and interest since the first report of an efficient flat heterojunction SM-OSC by Tang. ${ }^{1}$ New concepts like intentional doping of organic matrices with donor or acceptor molecules, ${ }^{2,3}$ dedicated charge carrier transport layers ${ }^{4}$ or the p-i-n $\operatorname{architecture}^{5}$ have paved the way for certified power efficiencies of $5.9 \%{ }^{6}$

While SM-OSC currently have slightly lower efficiencies compared to polymer-based ${ }^{7,8}$ and dye-sensitized $^{9}$ OSC, they are expected to be well-suited for mass-production by vacuum evaporation in in-line systems, as has been demonstrated for small-molecule organic light-emitting diodes (SM-OLED). Competitiveness to inorganic and other organic solar cells is expected due to weight, price (material consumption of $\approx 1 \mathrm{~g} / \mathrm{m}^{2}$ ), total device thickness of $(<1 \mu \mathrm{m})$ and ease of production.

Currently, in research and development of thin-film optoelectronic devices like SM-OLED and SM-OSC, the standard configuration involves a glass substrate coated with a pre-structured electrode of a transparent conductive oxide (TCO), typically tin-doped indium oxide $\left(\mathrm{In}_{2} \mathrm{O}_{3}: \mathrm{Sn}\right.$, or ITO) or aluminium-doped zinc oxide (AZO) ${ }^{10}$ TCO are typically deposited by sputtering and provide an excellent combination of transparency and conductivity. Nontheless, for inverted SM-OSC or SM-OLED deposited on an opaque substrate, illuminated or emitting light through the top, TCOs are not a suitable choice. Generally, TCOs are difficult to apply since sputtering onto organic layers damages the organic material underneath. They are brittle ${ }^{11}$ which inhibits use in flexible devices; the recent increase of demand for indium, e.g. for flat panel displays and high-tech applications, led to rising ITO prices in the last decade.

A possible alternative to TCO is ultra-thin metal, ${ }^{12-14}$ which can be thermally evaporated in vaccum and can be applied in the same inline-system as the organic small molecules. Al, Ag and Au thin films are interesting due to high transmittance in the visible range of the spectrum in case of thin layers. Closed layers, which are required for application in optoelectronic devices, also exhibit high conductivity. However, evaporation of thin metal films to form stable, continuous and level surfaces is a challenging task.

Obtaining a suitable morphology with low roughness depends on a variety of factors, e.g. metal type, temperature, evaporation rate, ${ }^{15}$ solvent treatment,${ }^{16}$ substrate, ${ }^{16-18}$ or surfactants. ${ }^{19-22}$ Also, the partial pressure of gases which might be present during evaporation can play a role, since the gases may slow down evaporated metal atoms, thus reducing kinetic energy and temperature. ${ }^{23}$ Due to the high number

Further author information:

J. Meiss, e-mail: jan.meiss@iapp.de, Phone: +49-(0)351-463-38773

K. Leo, e-mail: karl.leo@iapp.de

Organic Photovoltaics X, edited by Zakya H. Kafafi, Paul A. Lane, Proc. of SPIE Vol. 7416

741603 · (c) 2009 SPIE · CCC code: 0277-786X/09/\$18 · doi: 10.1117/12.826890 


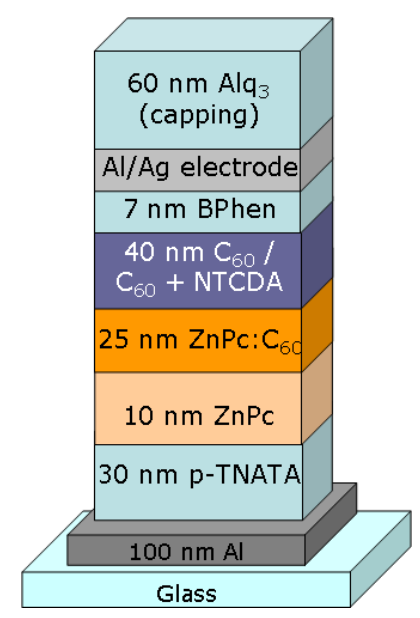

Figure 1. Schematic of the used solar cell stack, illuminated through the top; The HTL is p-TNATA. Intrinsic $\mathrm{C}_{60}$ or $\mathrm{n}-\mathrm{NTCDA}$ is used as ETL.

of parameters, different thicknesses for coalescence (the threshold between isolated islands and continuous layers, also referred to as percolation thickness) have been reported with values ranging between $2 \mathrm{~nm}$ and more than $15 \mathrm{~nm} \cdot{ }^{12,15,24,25}$ When fabricating optoelectronic devices with a transparent (metal) top contact, the performance can be increased by the presence of dielectric capping layers by utilizing a microcavity effect and improved light incoupling $\left(\mathrm{SM}-\mathrm{OSC}^{12,26}\right)$ or outcoupling $\left(\mathrm{SM}-\mathrm{OLED}^{27}\right)$. The microcavities in these cases are Fabry-Perot microcavities, since both electrodes consist of reflective metal (thick bottom Al anode; thin, semitransparent $\mathrm{Al} / \mathrm{Ag} / \mathrm{Au}$ anode), and aim at constructive interference for certain wavelengths which fulfil the resonator condition. The phase shift in the resonator is expressed as

$$
\Delta \phi=2 \sum_{i=0}^{m} \frac{2 \pi n_{i} d_{i}}{\lambda} \cos \theta_{i}+\sum_{j=0}^{l} \Delta \phi_{\text {layer }_{j}}+\Delta \phi_{\text {anode }}+\Delta \phi_{\text {cathode }}
$$

with $m$ organic layers having indices of refaction $n_{i}$, layer thicknesses $d_{i}$ and angle of propagation $\theta_{i}$ (resulting from angle of incidence and $n_{i}$ ), out of which there are $l$ layers having properties of an absorber, thus changing the phase. Eq.1 consists of optical retardation and phase shifts within absorbing layers and at reflective metal contacts. Optical simulations are a tool well-suited for optimization of solar cell stack and capping layer thickness. As Eq.1 shows, by employing transparent charge carrier transport layers (electron transoprt layers [ETL] or hole transport layers [HTL]) or transparent capping layers, the distribution of the optical field within the solar cell can be tailored such as to shift the maximum photon density into the absorber layers. ${ }^{28}$ This is important since the small exciton diffusion length of organic materials limits the absorber thickness in SM-OSC to well below $100 \mathrm{~nm}$, even down to only $\approx 10 \mathrm{~nm}$ for some materials like e.g. $\alpha$ - $\alpha^{\prime}$-bis(2,2-dicyanovinyl)-oligothiophenes. ${ }^{29}$ While simulations of organic layers can be performed with reasonable reliability, since $\mathrm{n}$ - and k-values can be determined by ellipsometry and optical measurements, simulations of ultra-thin metal layers are challenging. Simulations are necessary to accurately predict the distribution of the optical field within a solar cell. The current paper presents experimental and numerical studies of ultra-thin metal layers and capping layers on top-illuminated organic solar cells.

\section{METHODS}

\subsection{Experimental}

All samples were fabricated using shadow masks in a custom-made vacuum system (K.J. Lesker, UK) at a base pressure of $10^{-6}$ mbar. Float glass which was precleaned with detergents and organic solvents followed by oxygen plasma treatment was used as substrate. 

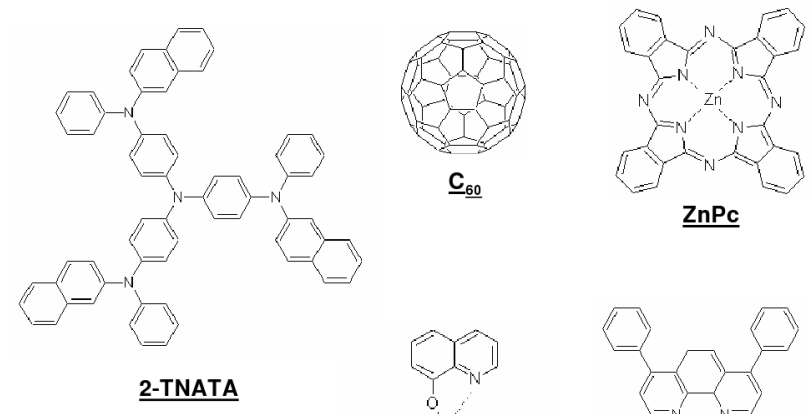

$\underline{\mathrm{ZnPC}}$
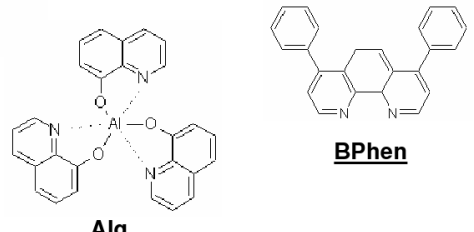

$\mathrm{Alq}_{3}$

Figure 2. Structures of the used organic materials 2-TNATA, $\mathrm{C}_{60}, \mathrm{ZnPc}_{\text {, }} \mathrm{Alq}_{3}$ and BPhen.

For solar cells, the layer sequence is illustrated in Fig. 1. The preparation was performed as follows: A metal back contact of $100 \mathrm{~nm} \mathrm{Al}$ was deposited, followed by $1 \mathrm{~nm}$ of a p-type dopant (Novaled AG, Dresden, Germany). ${ }^{30}$ As hole transporting material, $30 \mathrm{~nm}$ or $60 \mathrm{~nm}$ of $5 \mathrm{wt} \%$ p-doped 4,4',4"-tris(1naphthylphenylamino)-triphenylamine (TNATA) was used. As light absorbing material, layers of zinc phthalocyanine $(\mathrm{ZnPc})(10 \mathrm{~nm})$ and co-evaporated $\mathrm{ZnPc}_{6} \mathrm{C}_{60}(25 \mathrm{~nm}$, ratio 1:1) were deposited. After an additional absorber/transport layer of $\mathrm{C}_{60}(10 \mathrm{~nm})$, an electron transport layer either of $30 \mathrm{~nm}$ intrinsic $\mathrm{C}_{60}$ or of $30 \mathrm{~nm} \mathrm{n}$-doped 1,4,5,8-naphthalenetetacarboxylic dianhydride (NTCDA) was evaporated; $7 \mathrm{~nm}$ 4,7-diphenyl-1,10-phenanthroline (BPhen) was used as exciton blocker. The molecules are shown in Fig. 2. All materials had been purified at least twice by vacuum gradient sublimation. Different thicknesses and combinations of $\mathrm{Ag}$ and $\mathrm{Al} / \mathrm{Ag}$ were used as transparent top contact. In some cases, $60 \mathrm{~nm}$ of tris(8hydroxy-quinolinato)-aluminium ( $\mathrm{Alq}_{3}$ ) on top of the metal electrode increase light outcoupling out of the solar cell. ${ }^{12,26}$ Typical device areas are around $6.7 \mathrm{~mm}^{2}$ (measured using a light microscope).

16 samples were made on the same wafer in one run. This way, variations of top contact, HTL or ETL can be performed while keeping the deposition conditions for all other layers constant and reproducible.

Finished solar cells were encapsulated in a glovebox attached to the vacuum deposition chamber under nitrogen atmosphere, then stored at ambient conditions. $J(V)$-characteristics were recorded using a source measurement unit $236 \mathrm{SMU}$ (Keithley) under an AM 1.5g sun simulator (Steuernagel SC1200), monitored with a referenced silicon photodiode with respect to which intensities are given. The $J(V)$-data are not corrected for spectral mismatch. Previous experiments with similar devices suggest that the mismatch is close to unity due to the combination of the spectrum of our sun simulator, the spectral response of the reference diode and the $\mathrm{ZnPc}: \mathrm{C}_{60}$ absorber system.

\subsection{Optical constants}

Reflection and transmission measurements were performed on a Lambda $900 \mathrm{UV} / \mathrm{VIS} / \mathrm{NIR}$ spectrometer (Perkin Elmer) and a UV 3100 spectrometer (Shimadzu). Measured spectra were evaluated numerically by fitting optical constants in an iterative variation to reproduce the experimental results. This way, reflection $R$ and transmission $T$ were used to determine the index of refraction $n$ and the extinction coefficient $\kappa$, as is described below. Additional data were obtained by ellipsometry and, for metals, using the database of the commercially available ETFOS software (Fluxim, Swizerland). Typical data are shown in Fig. 3: the optical constants for commonly used absorber materials $\mathrm{C}_{60}$, $\mathrm{ZnPc}$ and blend layers of $\mathrm{ZnPc}: \mathrm{C}_{60}$ (1:1 ratio) and for several transparent materials important in the current context, TNATA, BPhen and $\mathrm{Alq}_{3}$. 

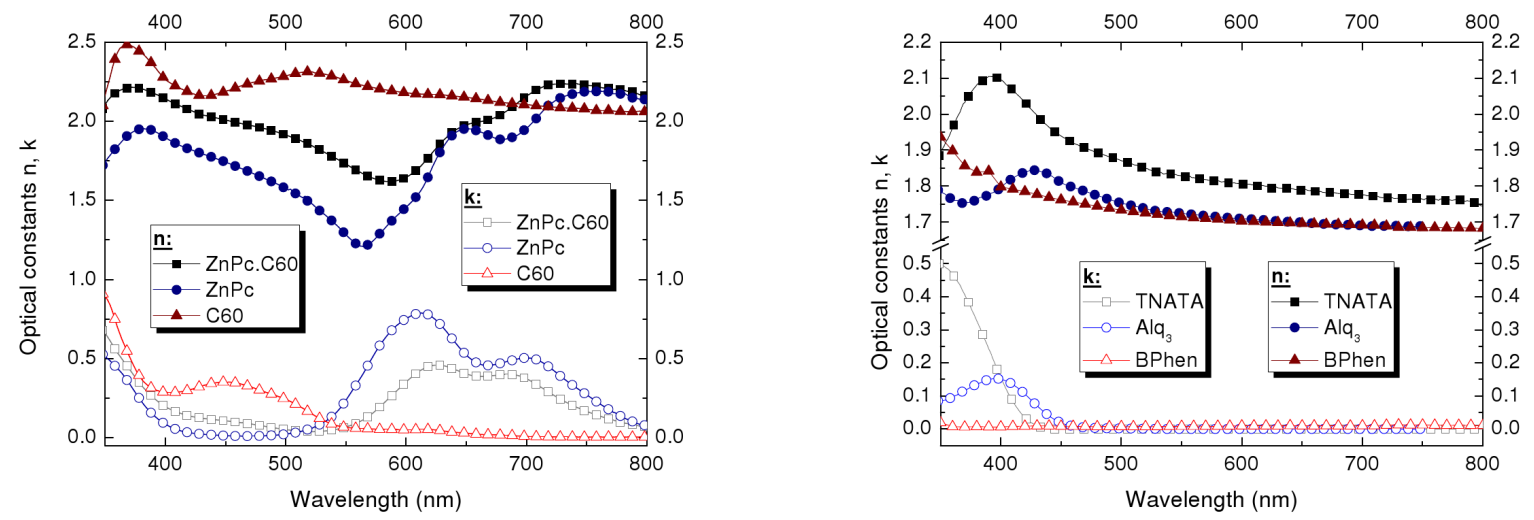

Figure 3. Left: Optical constants n (filled symbols), $\kappa$ (open symbols) of ZnPc: $\mathrm{C}_{60}$ (squares), ZnPc (circles) and $\mathrm{C}_{60}$ (triangles). Right: Optical constants $\mathrm{n}$ (filled symbols), $\kappa$ (open symbols) of TNATA (squares), Alqu (circles) and BPhen (triangles).

\subsection{Simulations: Transfer Matrix Formalism}

The transfer matrix formalism allows to calculate the change of amplitude of an electromagnetic field traversing a stack of $i$ layers having thicknesses $d_{i}$ and the complex indices of refraction $\hat{n_{i}}$ with

$$
\hat{n_{i}}=n_{i}+i \kappa
$$

which is related to the complex dielectric function $\hat{\epsilon}=\epsilon_{1}+i \epsilon_{2}$ by

$$
\epsilon_{1}=n^{2}-\kappa^{2}, \quad \epsilon_{2}=2 n \kappa .
$$

To describe different materials, different models are used for different material types, e.g. the Drude model for metals or the Lorentz-oscillator model combined with the Cauchy equation for organic materials within the visible spectrum. It is problematic to adequately simulate rough layers or intermixed networks of different materials which may occur depending on the deposition conditions. This is an issue for optoelectronic devices when metals are evaporated onto organic materials: metal atoms may penetrate into the molecular layer, creating a metal atom-doped organic layer. Another possibility is that materials grow with island-like morphology, having voids between clusters or crystalline grains. The Maxwell-Garnett model describes the dielectric constant $\epsilon$ of a matrix material having $\epsilon_{M}$ with $j$ inclusions having $\epsilon_{j}$ as

$$
\frac{\epsilon-\epsilon_{M}}{\epsilon_{M}+\left(\epsilon-\epsilon_{M}\right) L}=\sum_{j \neq 1} p_{j} \frac{\epsilon_{j}-\epsilon_{M}}{\epsilon_{M}+\left(\epsilon_{j}-\epsilon_{M}\right) L}
$$

Here, $L$ is a coefficient reflecting the geometry of the inclusions; $p_{j}$ describes the volume ratio of inclusions of material $j$ to the total layer volume. The current work employs the Effective Medium Approach (EMA) or Bruggeman model ${ }^{33}$ based on Eq. 4, which uses the effective dielectric function as the host medium for the inclusion, modifying Eq. 4 to

$$
0=\sum_{j} p_{j} \frac{\epsilon_{j}-\epsilon}{\epsilon+\left(\epsilon_{j}-\epsilon\right) L}
$$

Typically, in this work the Drude model is used for metal layers, the oscillator model for organic materials and the Bruggeman approach for rough layers or where voids, inclusions or material diffusion are 
expected. For a comprehensive description of the transfer matrix formalism, the interested reader is referred to Heavens. ${ }^{34}$

The approach used in the current work involves measurements of transmission, reflection and absorption of any given material; using these data and custom-made software programs "Multifit RT" 35 and "Multifit T", 36 the optical constants $n$ and $\kappa$ are determined. If material stack, layer thicknesses and the optical constants are known, simulations are performed using the software programs "Optics" ${ }^{37}$ and FilmWizard ${ }^{\mathrm{TM}}$ 32bit. ${ }^{38}$ Using these programs in combination, it is possible to simulate reflection $R(\lambda)$, transmission $T(\lambda)$ and absorption $A(\lambda)$ for a complete device, and additionally for each wavelength and any position in the stack field amplitude $E^{\lambda}(x)$, absorption $N^{\lambda}(x)$, and total absorption for all wavelengths $N(x)$, using the AM1.5G spectrum as input parameter.

\section{RESULTS}

\subsection{Thin metal layers}

A first step towards simulation of SM-OSC with ultra-thin metal top contacts is a systematic study of thin metal films: it has to be investigated to what extent the bulk optical constants of e.g. $\mathrm{Al}$ or $\mathrm{Ag}$ describe thin layers. For this purpose, 8 samples were created: 5, 10, 15 and $20 \mathrm{~nm}$ of $\mathrm{Al}$ or $\mathrm{Ag}$, respectively, evaporated on top of BPhen-coated glass. BPhen was chosen since in the actual devices, BPhen is the typical transparent exciton blocking layer (EBL) which is used between the active absorbing materials and the thin metal top contacts. The evaporation rates were $0.2 \AA$ for $\mathrm{Ag}$ and $0.8 \AA$ for Al, respectively. Reflection and transmission were measured experimentally and were then calculated with FilmWizard ${ }^{\mathrm{TM}}-32$ bit. The resulting data are shown in Fig. 4 and 5.
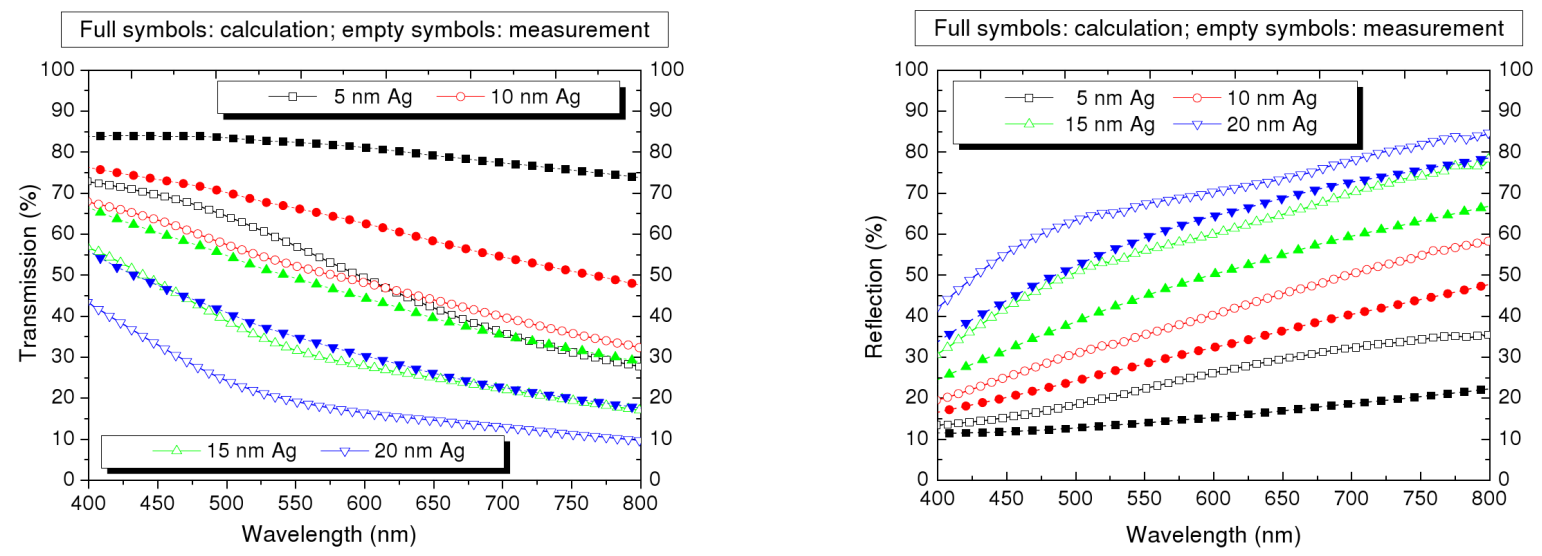

Figure 4. a) left: Transmission of thin Ag layers. b) right: Reflection of thin Ag layers.

Full symbols: calculation; empty symbols: measurement. Squares: $5 \mathrm{~nm}$; circles: $10 \mathrm{~nm}$; triangles: $15 \mathrm{~nm}$; upsidedown triangles: $20 \mathrm{~nm}$ layer thickness.

It is seen that for $\mathrm{Ag}$, the measured transmission is systematically lower for all thicknesses, so that a correct simulation using bulk optical constants is difficult for thin layers. Reflection data, on the other hand, show a general agreement in shape and magnitude of the curve. The deviations of experiment and calculation are especially large, even regarding the shape of the curve, for very thin (less than $10 \mathrm{~nm}$ ) layers.

Even larger deviations were encountered for ultra-thin Al layers. Films below the coalescence threshold (e.g., $5 \mathrm{~nm}$ thickness) exhibit deviations of the simulation from experimental measurements as large as 20$30 \%$ for reflection and transmission. However, the good agreement reached at film thicknesses of $>10 \mathrm{~nm}$ indicates that bulk constants are a useful approximation for Al films if they form closed layers.

The reflection of complete solar cell stacks (layer sequence as described in Fig. 1) was studied experimentally and in simulations. Fig. 6 (left) shows the sensitive dependence of reflection on composition of the metal 

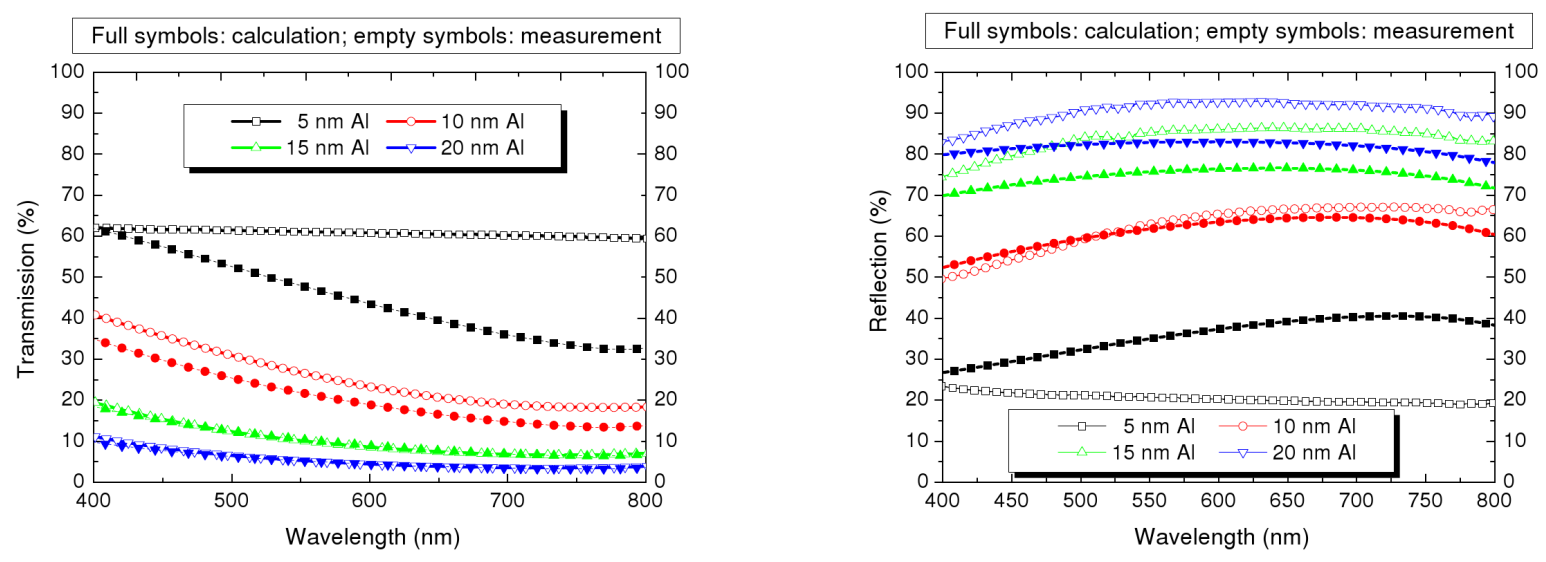

Figure 5. a) left: Transmission of thin Al layers. b) right: Reflection of thin Al layers.

Full symbols: calculation; empty symbols: measurement. Squares: $5 \mathrm{~nm}$; circles: $10 \mathrm{~nm}$; triangles: $15 \mathrm{~nm}$; upsidedown triangles: $20 \mathrm{~nm}$ layer thickness.

electrode and the influence of capping layers. It is visible that the reflection spectra change dramatically upon replacement of a $15 \mathrm{~nm} \mathrm{Ag}$ contact by a two-layer electrode of $5 \mathrm{~nm} \mathrm{Al} / 10 \mathrm{~nm} \mathrm{Ag:} \mathrm{reflection} \mathrm{is} \mathrm{decreased}$ in the range of $\lambda<500 \mathrm{~nm}$, but increased at $\lambda>600 \mathrm{~nm}$ (absorption regime of $\mathrm{ZnPc}$ ). Independent of the composition of the metal contact, addition of a capping layer reduces reflection by an absolute 20-30 \% over a wide part of the visible spectrum. Fig. 6 (right) displays an example of a comparison of devices simulated using bulk optical constants of $\mathrm{Al}$ and $\mathrm{Ag}$, compared with experimentally measured reflection. It is visible that $15 \mathrm{~nm}$ of $\mathrm{Ag}$ form a layer that can be described by bulk constants without qualitative errors, while a combination of $\mathrm{Al} / \mathrm{Ag}$ exhibited qualitatively and quantitatively erroneous results. It was found that especially for ultra-thin Al layers, great care must be taken when employing numerical methods for device optimisation.
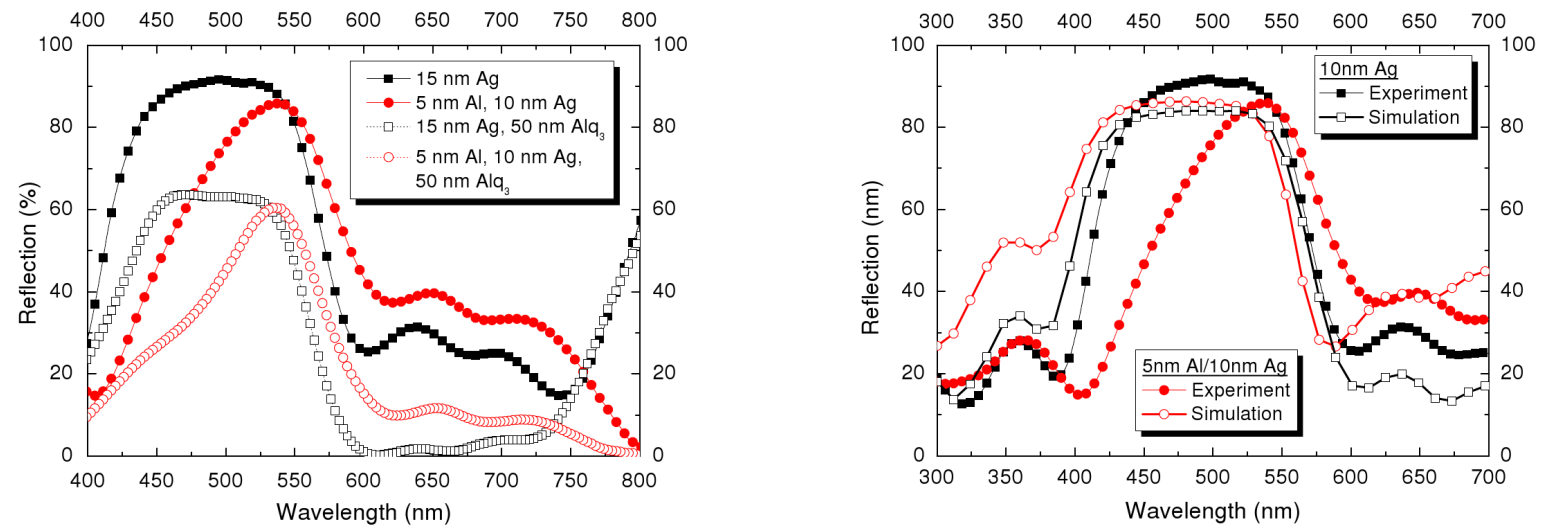

Figure 6. a) left: Influence of metal composition and capping layers on solar cells. Full symbols: no capping; empty symbols: $50 \mathrm{~nm} \mathrm{Alq} 3$ capping.

b) right: Comparison of experiment (full symbols) and simulation (empty symbols).

\subsection{Top-illuminated organic solar cells}

Finally, solar cells are presented in Fig. 7 which employ different HTL thicknesses and different ETL materials. Device characteristics are shown in Table 1. It is shown that there is a sensitive dependence of device 


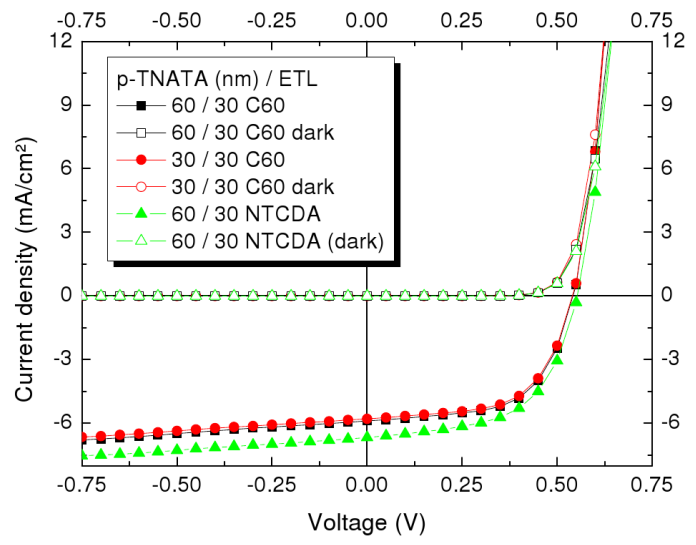

Figure 7. ITO-free top-illuminated SM-OSC, employing different HTL thicknesses and different ETL materials. Full symbols: under illumination; empty symbols: in the dark. The stack is shown in Fig. 1; varied are p-TNATA thickness (30 nm: circles; $60 \mathrm{~nm}$ : squares/triangles) and the ETL material ( $\mathrm{C}_{60}$ : squares/circles; NTCDA: triangles.)

performance on HTL thickness for a fixed ETL: upon increasing the thickness of the p-TNATA layer, the short circuit current density increases from $5.89 \mathrm{~mA} / \mathrm{cm}^{2}$ to $6.55 \mathrm{~mA} / \mathrm{cm}^{2}$. This is attributed to a better distribution of the optical field with an increased photon flux in the $\mathrm{ZnPc}$ and $\mathrm{ZnPc}: \mathrm{C}_{60}$ absorber layers. A concomitant increase of $\mathrm{V}_{\mathrm{oc}}$ is noted, which corresponds to an increased charge carrier density in the device leading to an increased splitting of the quasi-Fermi levels. As side effect, the increased density of photogenerated charge carriers also leads to a slight increase in recombination, lowering the fill factor $F F$ within experimental scatter from $60.5 \%$ to $59.9 \%$. Altogether, usage of a thicker HTL leads to an efficiency increase from $1.92 \%$ to $2.17 \%$.

Replacing $\mathrm{C}_{60}$ with the transparent, wide-gap organic material NTCDA reduces parasitic absorption. The intrinsic ETL $\mathrm{C}_{60}$ (which at the same time serves as absorber material) exhibits significant absorption at $\approx 450 \mathrm{~nm}$, but photogenerated excitons cannot be separated if the distance from the location of generation to the $\mathrm{ZnPc}_{\mathrm{n}} \mathrm{C}_{60}$ interface is much larger than the exciton diffusion length and are lost. Hence, exciton diffusion length is a limiting factor for $\mathrm{C}_{60}$ ETL layer thickness. This issue can be improved by employing NTCDA as ETL, which has no absorption in the visible part of the optical spectrum. An un-optimized device with $30 \mathrm{~nm}$ n-NTCDA exhibited a high photocurrent of $6.68 \mathrm{~mA} / \mathrm{cm}^{2}$, which is higher than even the short circuit current of the device with $60 \mathrm{~nm}$ TNATA and $\mathrm{C}_{60}$. Similar effects on $\mathrm{V}_{\mathrm{OC}}$ and $F F$ are noted as described above. However, since the device is not optimized for field distribution, the efficiency is slightly lower with $2.12 \%$ compared to the $\mathrm{C}_{60}$ devices. NTCDA demonstrates the potential of wide-gap materials and underlines the necessity of simulations for device optimisation by controlling the stack and layer thickness.

Table 1. Overview of presented solar cell configurations. In all cases, $7 \mathrm{~nm}$ BPhen (EBL) was used.

\begin{tabular}{|c|c|c|c|c|c|}
\hline $\begin{array}{c}\text { HTL thickness } \\
(\mathrm{nm})\end{array}$ & $\begin{array}{c}\text { ETL } \\
(\text { material })\end{array}$ & $\begin{array}{c}\mathrm{J}_{\mathrm{sc}} \\
\left(\mathrm{mA} / \mathrm{cm}^{2}\right)\end{array}$ & $\begin{array}{c}\mathrm{V}_{\text {oc }} \\
(\mathrm{V})\end{array}$ & $\begin{array}{c}\text { Fill factor } \\
(\%)\end{array}$ & $\begin{array}{c}\text { Efficiency } \eta \\
(\%)\end{array}$ \\
\hline 30 & $\mathrm{C}_{60}$ & 5.89 & 0.541 & 60.5 & 1.92 \\
\hline 60 & $\mathrm{C}_{60}$ & 6.55 & 0.55 & 59.9 & 2.17 \\
\hline 30 & $\mathrm{n}-\mathrm{NTCDA}$ & 6.68 & 0.553 & 57.34 & 2.12 \\
\hline
\end{tabular}




\section{CONCLUSION}

In the current work, we list influences of different processing parameters on film formation of metal layers and explain the advantages of employing metal layers instead of ITO as electrode materials for organic solar cells. The importance of simulations and interfaces is emphasized, describing thin metal films and capping layers as major factors. As example for utilization of optical properties, devices are presented where variation of layer thickness or reduction of parasitic absorption lead to improved performance. N-doped NTCDA is shown as viable alternative to the commonly used fullerene $\mathrm{C}_{60}$ for electron transport. Top-illuminated, ITO-free, small-molecule organic solar cells using doped transport layers with over $2 \%$ efficiency are demonstrated.

\section{ACKNOWLEDGMENTS}

This work is funded by the Bundesministerium für Bildung und Forschung in the framework of the InnoProfile project (03IP602).

\section{REFERENCES}

[1] C. W. Tang, Two-layer organic photovoltaic cell, Appl. Phys. Lett. 48(2), 183-185 (1986).

[2] K. Walzer, B. Maennig, M. Pfeiffer, and K. Leo, Highly Efficient Organic Devices Based on Electrically Doped Transport Layers, Chemical Reviews 107(4), 1233-1271 (2007).

[3] B. Maennig, J. Drechsel, D. Gebeyehu, P. Simon, F. Kozlowski, A.Werner, F. Li, S. Grundmann, S. Sonntag, M. Koch, K. Leo, M. Pfeiffer, H. Hoppe, D. Meissner, N. S. Sariciftci, I. Riedel, V. Dyakonov, and J. Parisi, Organic p-i-n solar cells, Appl. Phys. A-Mater. 79, 1-14 (2004).

[4] S. Pfuetzner, A. Petrich, C. Malbrich, J. Meiss, M. Koch, M. K. Riede, M. Pfeiffer, and K. Leo, Characterisation of different hole transport materials as used in organic p-i-n solar cells, Proceedings of SPIE 6999, 69991M-1 (2008).

[5] J. Drechsel, B. Maennig, F. Kozlowski, M. Pfeiffer, K. Leo, and H. Hoppe, Efficient organic solar cells based on a double p-i-n architecture using doped wide-gap transport layers, Appl. Phys. Lett. 86, 244102244104 (2005).

[6] $2 \mathrm{~cm}^{2}$ small-molecule organic solar cell, made by heliatek/IAPP, measured by NREL in 2009 as having $5.87 \%$ under standard reporting conditions.

[7] $0.86 \mathrm{~cm}^{2}$ polymer organic solar cell, made by Konarka, measured by NREL in 2009 as having $6.4 \%$ under standard reporting conditions.

[8] J. Y. Kim, K. Lee, N. E. Coates, D. Moses, T.-Q. Nguyen, M. Dante, and A. J. Heeger, Efficient tandem polymer solar cells fabricated by all-solution processing, Science 317, 222-225 (2007).

[9] Md. K. Nazeeruddin, T. Bessho, Le Cevey, S. Ito, C. Klein, F. De Angelis, S. Fantacci, P. Comte, P. Liska, H. Imai, and M. Graetzel, A high molar extinction coefficient charge transfer sensitizer and its application in dye-sensitized solar cell J. Photochem. Photobiol. A 185, 331-337 (2007).

[10] K. Schulze, C. Uhrich, R. Schueppel, K. Leo, M. Pfeiffer, E. Brier, E. Reinhold, and P. Baeuerle, Organic solar cells on indium tin oxide and aluminium doped zinc oxide anodes, Appl. Phys. Lett. 91, 073521-073523 (2007)

[11] Z. Chen, B. Cotterell, W. Wang, E. Guenther, and S.-J. Chua, A mechanical assessment of flexible optoelectronic devices, Thin Solid Films 394(1-2), 202-206 (2001).

[12] J. Meiss, N. Allinger, M. K. Riede, and K. Leo, Improved light harvesting in ITO-free inverted bulk heterojunction organic solar cells using capping layers, Appl. Phys. Lett. 93, 103311-103313 (2009).

[13] T. Oyamada, Y. Sugawara, Y. Terao, H. Sasabe, and C. Adachi, Top Light- Harvesting Organic Solar Cell Using Ultrathin Ag/MgAg Layer as Anode, Jpn. J. Appl. Phys. 46(4 A), 1734 (2007).

[14] R. B. Pode, C. J. Lee, D. G. Moon, and J. I. Han, Transparent conducting metal electrode for top emission organic light-emitting devices: Ca-Ag double layer, Appl. Phys. Lett. 84(23), 4614-4616 (2004).

[15] R. S. Sennett and G. D. Scott, The Structure of Evaporated Metal Films and their Optical Properties, J. Opt. Soc. Am. 40(4), 203-211 (1950).

[16] S. E. Roark and K. L. Rowlen, Thin Ag films - influence of substrate and postdeposition treatment on morphology and optical properties, Anal. Chem. 66(2), 261-270 (1994). 
[17] A. E. Duerr, F. Schreiber, M. Kelsch, H. D. Carstanjen, and H. Dosch, Morphology and Thermal Stability of Metal Contacts on Crystalline Organic Thin Films, Adv. Mater. 14, 961 (2002).

[18] V. Zaporojtchenko, K. Behnke, A. Thran, T. Strunskus and F. Faupel, Condensation coefficients and initial stages of growth for noble metals deposited onto chemically different polymer surfaces, Appl. Surf. Sci. 144145, 355359 (1999).

[19] J. Camarero, J. Ferron, V. Cros, L. Gomez, A. L. Vazquez de Parga, J. M. Gallego, J. E. Prieto, J. J. de Miguel, and R. Miranda, Atomistic mechanism of surfactant-assisted epitaxial growth, Phys. Rev. Lett. 81(4), 850 (1998).

[20] G. Rosenfeld, R. Servaty, C. Teichert, B. Poelsema, and G. Comsa, Layer-by-layer growth of Ag on $\mathrm{Ag}$ (111) induced by enhanced nucleation: A model study for surfactant-mediated growth, Phys. Rev. Lett. 71(6), 895-898 (1993).

[21] F. K. LeGoues, b. D. Silverman, and P. S. Ho, The microstructure of metalpolyimide interfaces, J. Vac. Sci. Technol. A 6(4), 2200-2204 (1988).

[22] A. Thran, T. Strunskus, V. Zaporojtchenko, and F. Faupel, Evidence of noble metal diffusion in polymers at room temperature and its retardation by a chromium barrier, Appl. Phys. Lett. 81(2), 244-246 (2002).

[23] J. M. Riveiro, P. S. Normile, J. P. Andres, J. A. Gonzalez, J. A. De Toro, T. Munoz, and P. Muniz, Oxygen-assisted control of surface morphology in nonepitaxial sputter growth of Ag, Appl. Phys. Lett. 89, $201902(2006)$.

[24] T. Brandt, M. Hoevel, B. Gompf, and M. Dressel, Temperature- and frequency-dependent optical properties of ultrathin Au films, Phys. Rev. B 78, 205409 (2008).

[25] C. G. Granqvist, Transparent conductors as solar energy materials: A panoramic review, Solar Energy Mater. Solar Cells 91(17), 1529-1598 (2007).

[26] B. O'Connor, K. H. An, K. P. Pipe, Y. Zhao, and M. Shtein, Enhanced Optical Field Intensity Distribution in Organic Photovoltaics, Appl. Phys. Lett. 89, 233502-233504 (2006).

[27] Q. Huang, K. Walzer, M. Pfeiffer, K. Leo, M. Hofmann, and T. Stuebinger, Performance improvement of top-emitting organic light-emitting diodes by an organic capping layer: An experimental study, J. Appl. Phys. 100, 064507 (2006).

[28] C. Falkenberg, C. Uhrich, S. Olthof, B. Maennig, M. K. Riede, and K. Leo, Efficient p-i-n type organic solar cells incorporating 1,4,5,8-naphthalenetetracarboxylic dianhydride as transparent electron transport material, J. Appl. Phys. 104, 034506 (2008).

[29] K. Schulze, C. L. Uhrich, R. Schueppel, K. Leo, M. Pfeiffer, E. Brier, E. Reinold, and P. Baeuerle, Efficient Vacuum-Deposited Organic Solar Cells Based on a New Low-Bandgap Oligothiophene and Fullerene $\mathrm{C}_{60}$, Adv. Mater. 18, 2872-2875 (2006).

[30] used for better processibility, comparable in performance to the commonly available 2,3,5,6-Tetrafluoro7,7,8,8-tetracyanoquinodimethane (F4-TCNQ); for a comparison of NDP2 and F4-TCNQ, see S. Reineke, F. Lindner, G. Schwartz, N. Seidler, K. Walzer, B. Luessem, and Karl Leo, White organic light-emitting diodes with fluorescent tube efficiency, Nature 459, 234238 (2009) and G. Schwartz, T. H. Ke, C. C. Wu, K. Walzer, and K. Leo, Balanced ambipolar charge carrier mobility in mixed layers for application in hybrid white organic lightemitting diodes, Appl. Phys. Lett. 93, 073304-073306 (2008).

[31] J. Wu, H. A. Becerril, Z. Bao, Z. Liu, Y. Chen, and P. Peumans, Organic solar cells with solutionprocessed graphene transparent electrodes, Appl. Phys. Lett. 92, 263302-263304 (2008).

[32] J.-Y. Lee, S.T. Connor, Y. Cui, and P. Peumans, Solution-processed metal nanowire mesh transparent electrodes, Nanoletters 8, 689-692 (2008).

[33] O. Stenzel, The Physics of Thin Film Optical Spectra. An Introduction., Springer Series in Surface Sciences, Berlin (2005).

[34] O. S. Heavens, Optical Properties of Thin Solid Films. Butterworth Scientific Publications, London (1955).

[35] T. Fritz, J. Hahn, H. Boettcher, Determination of the optical constants of evaporated dye layers, Thin Solid Films 170, 249 (1989). 
[36] R. Nitsche, Optical Properties of Organic Semiconductors, Dissertation, Dresden University of Technology, Dresden (2005).

[37] Developed by F. Kozlowski at the Institute of Applied Photophysics, Dresden University of Technology, Dresden.

[38] Developed by Scientific Computing International, Carlsbad, CA. 